\title{
Educational Background and High School Maths Teachers’ Specialism
}

\author{
Lin. Wang \\ Department of Mathematic and Information, China West Normal University, Nanchong, P. R. China \\ Email: wanglin321camil@163.com \\ Chang-huan. Feng \\ Department of Mathematic and Information, China West Normal University, Nanchong, P. R. China \\ Email: fchanghuan@163.com
}

\begin{abstract}
Teachers' Specialism is a world development trend and fashion, but also the needs and the direction of teacher education reform. After the latest curriculum reform, the educational reform and development of math, teachers have become universally concentrated and thoughtful in the field of mathematical education. The study adopting questionnaires and telephone interviews carried out a sample survey to 59 common high school math teachers from 3 provinces, and analyzed the connection between math teachers' specialism and educational background by the statistical analysis tool SPSS quantitatively and qualitatively. The study shows that both mathematical science knowledge and mathematical educational skills have an obvious connection with the educational background, while there's little connection between mathematical educational knowledge and the educational background. The study points out a relevant strategy which high school math teachers should attach the same important to pre-job training and post-job training
\end{abstract}

Index Terms - the latest curriculum reform, educational background, maths teachers' specialism, statistical analysis

\section{INTRODUCTION}

Teachers' Specialism is a world development trend and fashion, but also the needs and the direction of teacher education reform. The last century, after the mid$60 \mathrm{~s}$, there was a dramatic decline in birth rate around the world, and the demand for teachers was also greatly reduced, then the topic of improving the quality of teachers was on the surface. In 1966, the UNESCO and the International Labor Organization in Paris, France, convened the "status of teachers of the Special Intergovernmental Conference", adopted the "Recommendation Concerning the Status of Teachers ", which stressed the importance of the nature of the teaching profession, saying that "Teaching should be regarded as a profession. " From the last century since the 80's, "teacher", "teacher culture", "teacher education" has become a major area of educational research; and "teachers' specialism" has become a central concern in many countries and the focus as a main theme. Because

Manuscript received January 5, 2009; revised June 12, 2009; accepted July 6, 2009. of these, the world's teachers' specialism movement has risen and improved the quality of education as a protection. In 1996, the UNESCO 45th International Conference on Education held in Geneva. The meeting took "Strengthening the role of teachers in a changing world" as its theme, and "teachers are convinced that occurs in all types of schools and classrooms at all levels and through all educational channels as the key activities in educational reform", and "raising the status of teachers in the overall policy, specialism is the most promising long-term strategy". This gives us a major revelation: the teachers who will hold the 21st century' sun in the future, must receive specialized training, and have a higher professionalim as education professionals. The most influential research on teachers specialization overseas is the seven types of analytical framework about teacher's professional knowledge proposed by Lee Shulman in 1987[1-2]. After that, Grossman classified the teacher's specialized knowledge into six categories on the basis of Lee Shulman's research [2-3]. Some scholars in China have also studied the knowledge structure of teachers and drew some main points of view. For instance, Professor Wei-he XIE classified teachers' specification into 3 parts-the knowledge of students, the knowledge of curriculum, the knowledge and technique of teaching practice. Professor Chong-de LIU and Ji-liang SHEN classified it into 4 parts including subject-matter, condition, practical and cultural knowledge [4]. Maths teachers' specialism to teachers is a growingly-up specialized process aiming to the excellent of mathematics educational professionals, ranging from lifelong professional training, gaining educational knowledge and skills, showing professional ethics to improving the integrated lives through their entire career [5]. The latest curriculum reform puts forward more demanding requirement on the width and depth of math teacher's integrated qualities, thus the development of math teachers' specialism set in the new mathematical curriculum reform has more conspicuous urgency and epochal characteristics. Math teachers' specialism, at this stage of exploring, is a research direction of mathematical education. It not only relates to whether individual teachers can adapt reform, but is one key factor in the success of the reform. 
Owing to the simple operation, the SPSS (the Statistics Package for Social Science) is applied in various fields, such as economy, management, medicine, agronomy, engineering, etc [6]. And the application in educational fields is also very convenient, prompt, concise and practical. This study, by adopting questionnaires and telephone interviews, by virtue of software SPSS, made quantitative and qualitative analyses about the connection between high school math teachers' specialism and the educational background.

\section{RESEARCH SUBJECTS AND METHORDS}

\section{Research subjects}

The research subjects are made of 59 common high school math teachers from Shandong Province, Sichuan Province and Guangdong Province.

\section{Methods and process}

75 self-designed questionnaires were delivered and 59 were responded (the response rate was $78.7 \%$ ). The questionnaires include personal basic information (gender, age and educational background), mathematical scientific knowledge (mathematical modeling, Boolean algebra, optimum-seeking method, overall planning method, matrix, risk-based decision-making, spherical geometry, elementary number theory, etc), mathematical educational technological knowledge (the use of PPT, Word, Authorware, SPSS, CAI) and mathematical educational knowledge (including constructivism theory, problem-solving theory and the principle of independence, investigation, cooperation, etc). All of the data will be analyzed by SPSS quantitatively and qualitatively, so as to research the impact of educational background on high school math teachers' specialism levels. It mainly includes simple statistical analysis and partial correlation analysis.

1) Simple statistical analysis.

First of all, analyze all the data by SPSS. According to Fig.1 (Pie), most high school math teachers have bachelor's degrees or above, and only a few individuals have three-year's degrees. According to Fig.2 (Bar), nearly 2 / 3 teachers with master's degrees or above are young teachers below 27-year-old, and about $1 / 3$ teachers between the age of 27 and 45; more than 50\% teachers with bachelor's degrees are middle-aged young teachers, followed by the group of young teachers; almost all the teachers with three-year's degrees are elder teachers with the age of over 45-year-old. From the results of the analysis, the number and the proportion of high school math teachers with master's degrees are both increasing, that is to say, the teachers' educational background level is improving.
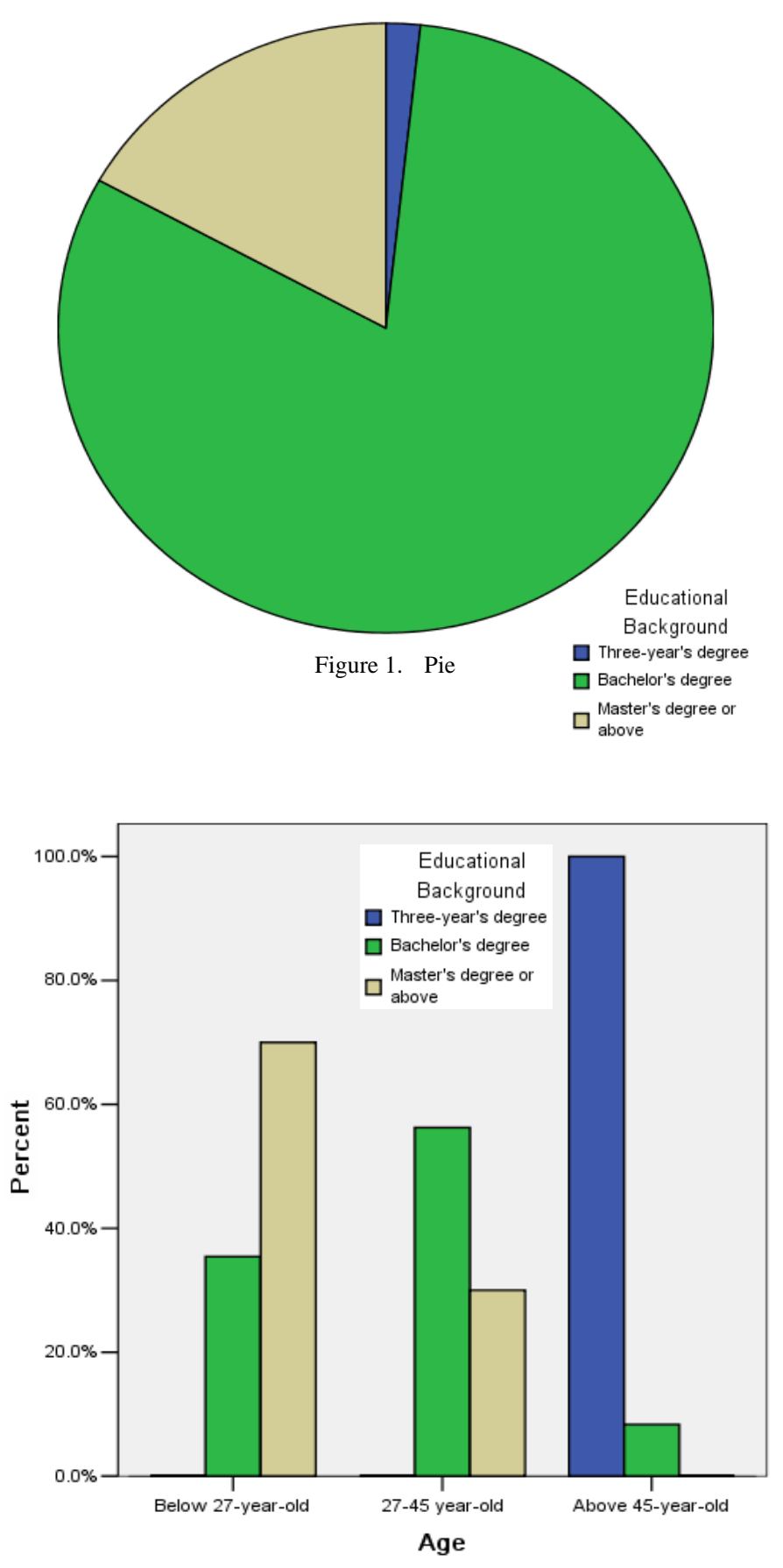

Figure 2. Bar

And then, run program Graphs Bar respectively, output Fig.3, Fig.4 and Fig.5. From these figures we can roughly get the mathematics scientific knowledge and technique both has connection with the educational background, but there seems to be no significant connection, between the mathematical educational knowledge and the educational background. In addition, teachers fail to fully grasp the educational knowledge in general. 


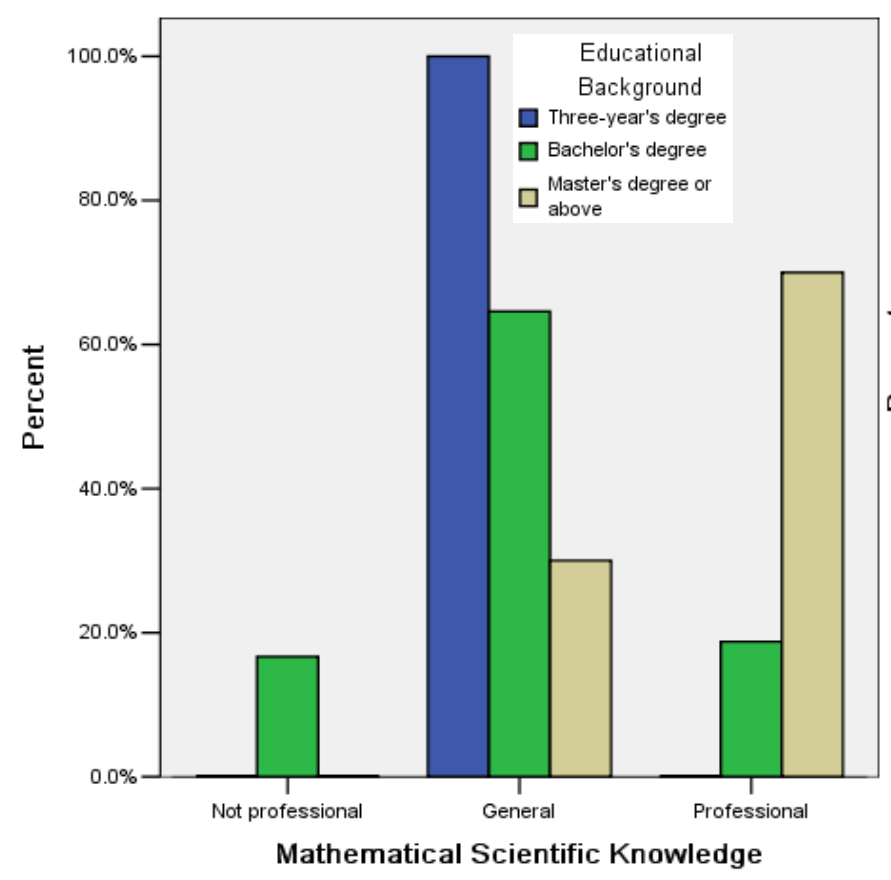

Figure 3. The bar of connection between mathematical scientific knowledge and educational background

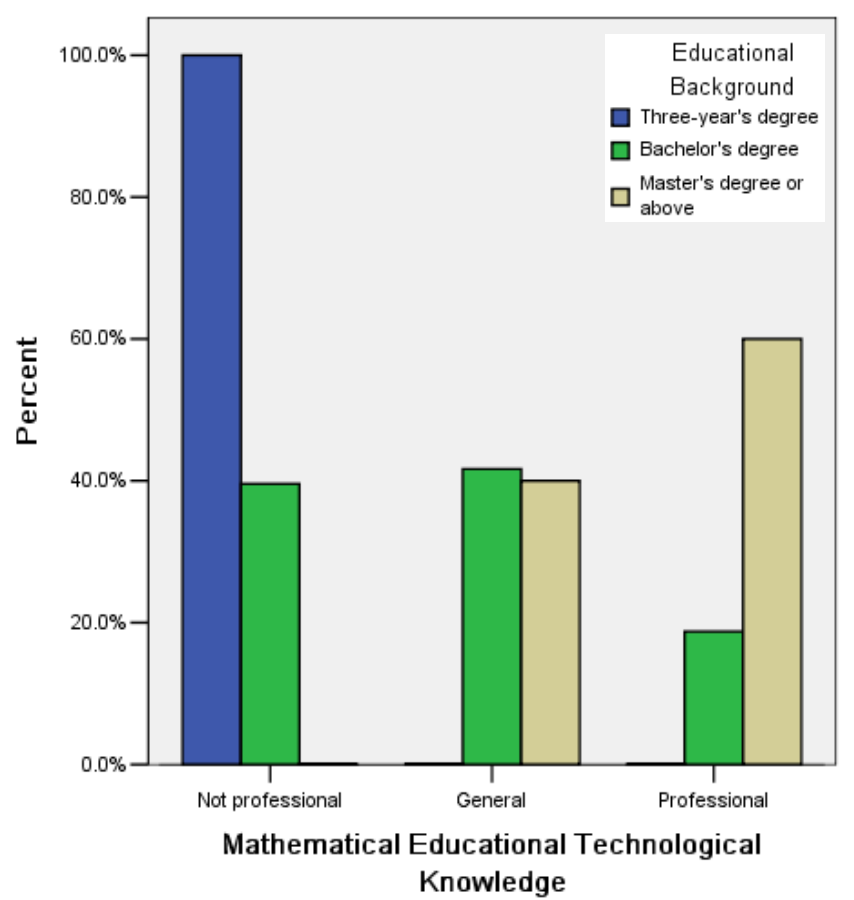

Figure 4. The bar of connection between mathematical educational technological knowledge and educational background

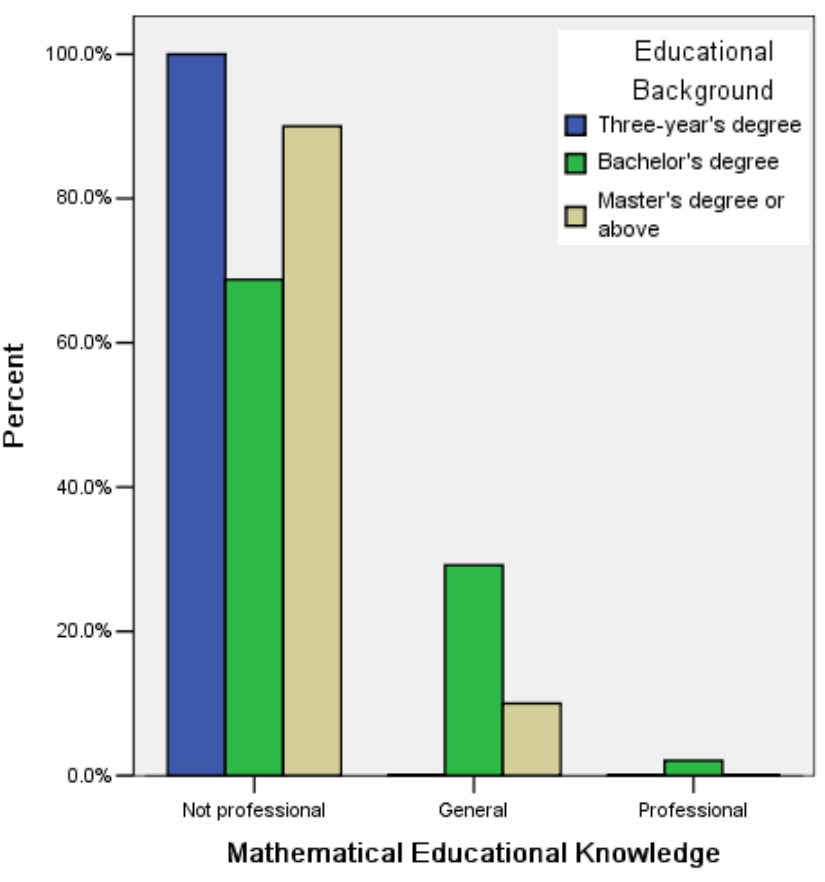

Figure 5. The bar of connection between mathematical educational knowledge and educational background

2) Partial correlation analysis.

In this study, there are 59 common high school math teachers, from 3 provinces, consisting of 37 women and 22 men, whose ages are divided into 3 sessions. Therefore, in order to make further quantitative analysis of the results of 2.2.1, we need to exclude these factors (including province, gender and age), even though they inevitably have some certain influence on research results.

Run program Analyze $\rightarrow$ Correlate $\rightarrow$ Partial, get table I , as follows:

TABLE I. CORRELATIONS

\begin{tabular}{|ccl|r|}
\hline Control Variables & & $\begin{array}{r}\text { Educational } \\
\text { Background }\end{array}$ \\
\hline & Mathematical & Correlation & .358 \\
& Scientific & $\begin{array}{l}\text { Significance(2- } \\
\text { tailed) }\end{array}$ & .007 \\
& Knowledge & df & 54 \\
\cline { 2 - 4 } Provinc & Mathematical & Correlation & .319 \\
e\& & Educational & Significance(2- & .017 \\
Gender & Technological & tailed) & 54 \\
\& Age & Knowledge & df & \\
\cline { 2 - 4 } & Mathematical & Correlation & -.079 \\
& Educational & Significance(2- & .562 \\
& Knowledge & tailed) & 54 \\
& & df & \\
\hline
\end{tabular}

By the partial correlation analysis, we can get the connection between math teachers' specialism and educational background with no consideration about the effect of province, gender and age. According to table I , the partial correlation coefficient of mathematics scientific knowledge and educational background is 0.358 , which reveals the degree of the connection between them is rather low $(0.30 \leq 0.358 \leq 0.50)$, and the significance 
level Sig. $(2-$ sided $)=0.007<0.05$ shows that there exists detection limit between them. So is the twomathematical educational technique and qualification, its partial correlation coefficient is 0.319 and the Sig. $(2-$ sided $)=0.017<0.05$. But in terms of mathematical educational knowledge and qualification, its partial correlation coefficient is -.079 , and the Sig. $(2-$ sided $)=0.562>0.05$, which tells us there is not significant difference at all. Of course, all the conclusions above are based on the premise of eliminating the influence of those three variables.

\section{THE ANALYSIS OF THE RESULTS}

\section{The diversity of qualifications}

Judging by the statistical analysis of the high school math teachers' specialism level, mathematical scientific knowledge as well as mathematical educational technique has conspicuous connection with qualifications, neither does mathematical educational knowledge, and the partial correlation analysis also got the same conclusion. So postgraduates, in relation to graduates, have better grasps of disciplinary knowledge with broader and further coverage, and are more capable of researching. Owing to the majority of professional curriculum planned for postgraduates is based on the 4-year degree course, math teachers with masters' degrees have advantage of mathematical knowledge and educational skills. However, there's no sign of obvious advantage in mathematical educational knowledge. The main reason is that these teachers tend to fix all their concentration on the mathematical scientific knowledge during doing the masters' degrees, while most of their mathematical educational knowledge is accumulated in the practice of teaching. At the same time, there is another problem exposed in questionnaires that it's rather common to find the theory and practice of teaching are divorced with each other, and the level of math teachers' specialism not keeping up with the times' development is right a decisive factor that constrains the curricula reform.

The qualification frames of teachers in different schools and regions exist difference of different degree, but over in over, teachers with bachelors' degree dominate, while teachers with three-year's degrees are withdrawing the occupations gradually, and the number and position of teachers with masters' degrees or above are growing year by year, it just fits the international trend of high-qualificationism in the development of educational levels.

\section{Attaching important to pre-job training and post-job training}

In the research, it is found that most math teachers have no time and energy to improve their professionalism, and hold attitudes of comprehension towards reform. As we know, the forming and the development of long-life learning system, and the link-up of pre-job training and post-job training can tremendously accelerate the selfrenewed of teachers' knowledge, enhance the capacity of theory and practice, and also efficiently ward off the aging of teachers' knowledge. Thus, the institution of practical teachers' training system proves to be particularly crucial. We should provide diverse training courses aimed at different individuals and their demands, such as recruit training, staff training, professional subject training, new educational thought training, qualification training, etc; also, we can advocate multi-formation training, like on-line training [7]. Only if possessing related professional level, math teachers could carry out new thoughts, new knowledge and new methods of curriculum criteria into teaching, and ensure bring mathematical quality education into effect.

It is the advice on how to improve teacher quality and development. On the base of investigational analysis and the factual demands of teachers' education and their professional development, the thesis gives some constructive advice. Study shows that most teachers show active interest in leaning and development, hoping to improve their scholastic level, promoting professional growth, enhance their quality and reaching the growing aim. On one hand, from the source of impetus, the improvement of teacher quality comes from their driving force. The concept change of teachers, teacher becoming researcher and improving their reflection capacity are the effective way to improve their quality. On the other hand, the driving force comes from schools, social, policy and students. The problem of teacher education is the lack of the normal and practical teacher education standard system. The thesis establishes the key to the development of teacher education institution and system is to build a series of cultivating model of teachers' preservice training, in-service training and the integration of the two. The finance support from the state movement is the must to build teacher educational system. The effective outside way to fulfill the teacher professional development is to guarantee the professional way on the policy, to provide the back of law, to build the mechanism of evaluation of teacher quality and competition, soft and hard environment building in the schools and cooperation resources from all sides.

Through interviews, there are a variety of factors which impact take highly educated teachers participated in training. Take the driving force of teachers' highly educated self-education into three categories: the need for the community as a whole from the macro-dynamics; the need for the school concept; individual needs of teachers' the micro-power. Then, the teachers who take part in studies well-educated are for the three power' interactions and the formation of the joint [8-13].

1. Teachers participated in training are highly educated and are less than the force. Society as a whole performance of macro-dynamics and the role of needless to say, but this need is not translated into the need of good schools and teachers. A considerable number of schools and individuals are still conducive in improving the transition rates to determine what kinds of behaviors that teachers should take participated in. And the relationship between work and study is in contradictions, 
which results in teachers' self-education less than the force. This is the main reasons for the grim situation.

2. School differences in the concept of power. Macrosocial motivation of teachers through the micro-dynamic concept of motivation in school linking, in view of the role of connecting power play. In reality, the micropower of more teachers in schools affected by the concept of power-driven, and the school leadership will be the attitudes and behavior of teachers about the learning situation. The survey shows that in economically developed areas, whether economic or poverty-stricken areas, have a high school education is the support rate.

3. Part of the teachers is weak in micro-power. The needs of individual teacher to enhance is internal, whether social, academic high school education for teachers on how strongly the request, and ultimately the individual must be implemented in the hearts of teachers strong demand, the implementation of the highly educated self-education teachers to take part in the action. In the reality, part of the teachers to participate in highly educated training are due to a clear understanding of the practice, lack of action, the more difficult to think, the lack of enthusiasm, all above reasons lead to why there is a lot of teachers not to participate in training for the highly educated.

Valuable experience, main method of work that educational background accumulates in elementary education process as follows:

The teacher strengthening practice teaching, cooperating with middle school, building graduate student educational background trains a base, makes rubbings from exhibition outside the school high grade teacher resources for education. Build the graduate student educational background teacher training a base the important trial being that Nanjing Normal University probes the modern teacher educational scheme. The professionalization teacher educates organization to need and middle school forms intimate buddy relation, platform needing to build the high-caliber teacher in linking the process that big learning and middle school special field carry out up growing up. Effect accepting the resources for education finiteness, existence is burning between tradition height division and middle and primary school achieving commonly, unitary one's own post value chooses face. School and the servant unit the aspect have complementary advantages and link up in personnel training. The teacher that has one basic closes educates feasible system tradition height division to be difficult to step off the "ivory tower" finding relief in, middle and primary school is also ask for self's enrollment quotas but single-faceted developing. In the course building modernized teacher educational scheme, we are necessary "in having composed religion, on reviving "pedagogy; teaching method" proposed by $\mathrm{Mr}$. Tao Xing Zhi compose be at school", the idea "that teaching does-in-one " still is that normal school universities and colleges and middle and primary school create the close relationship link, for the professionalization that the teacher educates provide special field practice support, realize colleges and universities and the employing unit have complementary advantages in the field of personnel training and link up.

Establish specialized teacher's educational institution. Enter the new century, adopt the century-old tradition of normal school as heir, and discard the old ways of life in favor of the new, and regard it in accordance with the open and flexible modern teacher's education system to set upping as the requirement, strengthen teacher's educational construction of base, has set up special teacher's institute of education in the frame system of totalization of discipline. It is in this way that the comprehensive university started teacher's educational reform has added one sum of excellence which has a special individual character. At present, assert teacher's qualification can't be as a kind of administrative affairs briefly towards the society, one organization of government asserts, can consider combining with such specialized teacher's educational institution and entrusting to the corresponding right, let every one have ambition, engaged in teacher a professional one normal student can to select and train similar high-level professional organization, in order to improve the specialized level that a teacher trains.

Put three tutorial systems into practice; keep good control on the mass that graduate student educational background elementary education teachers' trains. The tutorial system is to respect the student individual difference, to train one kind of effective system of highlevel talented person. Build high-caliber one graduate student director team, be the key training the high-caliber teacher's. For this purpose, Nanjing Normal University breaks the artificial border between university and middle school, and assume the position of graduate student education practice instructor in have engaged excellent more than 40 teacher of special grade of middle school and high-grade base school teacher according to nimble mechanism "not seeking possessions, what being used " disregarding location, only ask, discipline director having engaged 13 discipline education direction in school inner, also has allocated corresponding learning person to contact, has worked out and made a director clear duty for every graduate student at the same time in inside of academy. Than teacher and student that the graduate student educates how far, over ranging to have reached 3 of 1 , the graduate student expands the teacher and student ratio confessing decreasing rapidly under circumstances. Three tutorial system putting into effect, have the excellent director team who is tied in wedlock each other in the concurrent post building one theory and carrying out the close connection, end in mind, the multiple echelons flyover leading learns in relation, the group making great efforts with excellent director trains excellent elementary education teachers between building the director and the student on the basis respecting the student individual difference sufficiently.

Ascertain that science develops a Taoist temple, boosting the professionalization that the all-round teacher special field quality harmonious development teacher educates already becoming one kind of fundamental make for , the person inherent value of current teacher 
education policy lies in the go after the high-caliber teacher. Height mass education needs to have the highcaliber teacher; the teacher depending on the high tone professionalization educates high-caliber teacher culture to use personal influence. International Labor Organization and United Nations education, science and culture have been organized in "the suggestion about teacher position" in 1966, the form professionalization, with the patent to the teacher, has made explanation clear and definite first: "Should look upon educational work as special occupation, this occupation requires that the teacher be strict, sustained study about passes, gain and keep special knowledge and the special technology. The high-caliber teacher must be professionalization's, the teacher growing up needs the process that culture and system experiencing a professionalization train, this is the independent of man's will objective law. Teacher basic law educating the policy working out to ought to abide by a teacher growing up, this is to ascertain that science develops concre watching embody. The fundamental value being to be originally that the teacher educates policy with person is taken face. As the general policy that teacher professionalization develops,science develops a Taoist temple emphasizing to insist on people oriented; people foremost , sets up the all-round , be in harmony, sustainable development Taoist temple, promotes economy society and people's all-round harmonious development. The teacher is educated to be people-oriented cause, education is of fundamental importance to the fulfillment of our great long-range mission as the saying goes; educate the major program of lasting importance, the teacher to be this. The teacher is educated to be people-oriented cause, education is of fundamental importance to the fulfillment of our great long-range mission as the saying goes; Educate the major program of lasting importance, the teacher to be this. People's nature is all human relations in society sums, as a result, improve a teacher the development that all-round of directing people, enriches in the last analysis, and people's latent energy, individuality and the creativeness fine educating mass spread out.[14-16]

Teacher quality has "a double major", science develops a Taoist temple guiding lower teacher in special fields to develop ought to be one kind of even harmonious development. Professional staff is naturally the same as professional staff, the teacher with other industries, has certain discipline knowledge in hand, has the academic nature that special field develops. Learning is lifeline of tall teacher universities and colleges, driving force being also that teacher special field develops. At the same time, teacher special field has self's particularity, namely "how to teach", have the certain education professional knowledge in hand, train normal school. This teacher occupation double major is any teacher ought to have special field gives consideration to both be obliged to first, second in developing a course, help each other forward , harmony develop in the teacher.

\section{Validity and applicability of the research}

First of all, the study involves 59 common high school maths teachers from 3 provinces, the sample's coverage and amount is comparatively small. There's one teacher with three-year's degree, so the searching results are not applicable in all areas. Secondly, the research is based on teachers' subjective attitudes which are inevitably kinds of different from their real levels. Moreover, some teachers suggested that the scope and degree of the questionnaire should be complemented and modified. In addition, schools' attitude to the new curriculum reform, the conditions of teachers' training in different regions, and the teaching quality of universities which cultivate teachers and so on, all the factors have more or less influence on the researching results. Mathematical teacher' sex has effect on the evaluation about different channel's contribution to the improvement of professional quality. But teaching period, professional titles and diploma have notable effect on their evaluation[17-20]. The tables of "Number of Full-time Senior Secondary School Teachers by Subject Taught \& Educational Attainment” which have shown the data form the year 2001 to 2006 are as follows:

TABLE II. NUMBER OF FULL-TIME SENIOR SECONDARY SCHOOL TEACHERS BY SUBJECT TAUGHT \& EDUCATIONAL ATTAINMENT (UNIT: IN PERSON)

\begin{tabular}{|c|c|c|c|}
\hline Educational & 2001 & 2002 & 2003 \\
\hline Graduate & 946 & 1369 & 1629 \\
\hline Under-graduate & 98056 & 112523 & 131669 \\
\hline Associate Bachelor & 31085 & 33435 & 34811 \\
\hline High school Graduate & 501 & 465 & 418 \\
\hline $\begin{array}{c}\text { Below High School } \\
\text { Graduate }\end{array}$ & 10 & 8 & 6 \\
\hline Total & 130598 & 147800 & 168533 \\
\hline
\end{tabular}

Nevertheless, the study reflects the weaknesses and strengths of teachers with different educational backgrounds in teachers' specialism of high school math teachers; what's more, it gives teachers and teachers' training organization some help in pre-job training and post-job training.[21,22] Besides, the survey reveals that the state of teachers' professional knowledge is not optimistic, and the depth and width of professional knowledge are in great need of enhancing. Eventually, teachers should particularly put enough weight to the mathematical educational knowledge.

The teacher' professional development, which is characterized by improving teachers' inner professional quality and professional practice, has become the central topic of teachers' specialization and is gradually becoming the focus people attach importance to and one 
of central issues among contemporary educational reform [23-25]. The implementation of quality education in mathematics and spreading of new mathematical curriculum in our country set an even higher demand on mathematical teacher's professional quality. But the present situation is that mathematics teachers can not meet the demands. Consequently, it is urgent to study how to improve mathematics teachers' professional quality.

TABLE III. NUMBER OF FULL-TIME SENIOR SECONDARY SCHOOL TEACHERS By SUBJECT TAUGHT \& EDUCATIONAL ATTAINMENT (UNIT: IN PERSON)

\begin{tabular}{|c|r|r|r|}
\hline \multicolumn{1}{|c|}{ Year } & 2004 & 2005 & 2006 \\
\hline Bducational & & & \\
\hline Graduate & 2144 & 2504 & 2898 \\
\hline Under-graduate & 153584 & 175389 & 193138 \\
\hline Associate Bachelor & 32507 & 28230 & 24641 \\
\hline High school Graduate & 306 & 279 & 219 \\
\hline Below High School & 3 & 1 & 2 \\
\hline Graduate & & & \\
\hline Total & $2 \mathrm{E}+05$ & 206403 & 220898 \\
\hline
\end{tabular}

REFERENCES

[1] Shulman.L.S. "Knowledge and Teaching: Foundations of the New Reform,” Educational Review of Harvard. 1987, Vo1. 22..

[2] L. Y. Zhang, "Investigation of the Status and Research about the Expertise of High School Mathematics Teachers in Poverty-Stricken Area," unpublished.

[3] Grossman.P.L. "Teachers' Knowledge. In T.Husen \& T.N.Postlethwaite (Eds),” The International Encydopedia of Education, New York, 1994, pp. 56.

[4] C. X. Ming, "Practical Knowledge: The Basic Knowledge of Teachers' Specialization Development," Educational Review of Peking University. Peking, January 2003, pp. 105.

[5] Y.L. Jun, "Concept and Implementation of Mathematics New Curriculum,” Zhejiang University Press. Hangzhou, July 2005, pp. 87.

[6] M. Q. Guo, "Managements and Statistics,” Science Press. Peking, 2007, pp. 79-83.

[7] L. Zhou, "Investigation and Analyze about the Conditions of Primary and Middle Schools' Teachers in Beijing," Ji Nan, Adult Education, September 2007, pp.21.

[8] 1.Butlre,J. (1992). Teacher professional development: An Anstralian case study. Journal of Education for Teaching, 18(3).

[9] 2.Butt, Richard L., \& Raymond. (1989) Studying the Nature and DeveloPment of Teachers' Knowledge Using Collaboretive Autobiography. International Journal of Educational researeh.Vol.13.

[10] 3.Darling-Hammound,L.(ed).(1994).Professional development schools: Schools for developing a profession. NewYork: Teachers College Press.
[11] 4.Flinders,D.J.(1988).Teaeher isolation and the new reform. Journal of Curriculum and Supervision,14(1).

[12] 5.Goodson,Ivor.(1994).Studying the Teacher's Life and Work. Teaching and Teacher Education, Vol 10.No.1

[13] 6.Hensen,K.T.(1996). Teachers as Researchers. In J.Sikula.T.J.Buttery, \&E.Guyton (Eds) Handbook of Research on Teacher Education (2nd ed., pp.53-64) New York: Simon \& Schuster.

[14] Berliner D.C. Expert knowledge in the pedagogical domain. Paper presented at the meeting of the American educational psychological association [M]. New Orleans, LA. August 12,1989.

[15] Borko , H.\&Putnam,R.T. Leaning to teach , In David C.Berliner \& Robert C. ( alfee Eds.), Handbook of educational psychology [M]. New York: Macmillan, 1996.

[16] L Leavitt, Howard b. Issues and Problem in Teacher Education: an international handbook. New York: Greenwood Press,1992.

[17] Joseph W.Newnar. America's Teacher: an introduction to education, New York: Long-man, 1990.

[18] Evans,K. School Based Inservice Education: Case Studies and Guidelines for Implemention, 1993.

[19] Wilson J.C.(1926).Statement and Infexence (vol.1). Oxford,England: Oxford University Press.Prichard H.A.(1950).Knowledge and Perception: Essays and Lectures Oxford $>$ England:Oxford University Press.

[20] Fred Nickols(2000).Industry Analysis a la Michael Porter. Retrieved March 21 , 2003 , from http://home.att.neblnickols/fivewe forces.htm.

[21] Karl Mannheim. Man and Soeiety in an Age of Reeonstruction. London: Routledge and Kegan Paul.1951.

[22] Joseph Ftideman , Jona than Silberman. University Technology Transfer: Do Incentives, Management, and Location Matter. Journal of Technology Transfer, 2003.

[23] Bergqulst.W.H.\&Phillips.S.R. A Handbook for Faculty Development(Volume3). Washington D.C: The Council of Independent Colleges, 1981.

[24] Lee.Shulman. From Minsk to Pinsk: Why A Scholship of Teaching and Learning. Journal of scholship of Teaching And Learning,2000.(l).

[25] Fleteher.J.\&Patrick,S.K. Not Just Workshops Anymore: Theory of Faculty Development in Reframing Academic Priorities. IJAD3,1997.(1).

Lin Wang was born in 1984, Shandong Qingdao. She has graduated from teacher college of Qingdao university, and received bachelor degree in mathematics. Presently, she is a master graduate in the department of Mathematic and Information in China West Normal University. She majors in teaching theory, mathematics education and in the field of statistics.

Once publicized in the core journal publishes dissertation several, and succeeds by ISTP, EI the retrieval.

Once many times attended the domestic mathematics education aspect conference and related training, presently is engaged in the elementary mathematics educational work.

Chang-huan Feng Firstname B. Lastname was born in 1972, Sichuan Nanchong. Overall Planning and Economic Mathematics, master tutor, Professor of Department of Mathematic and Information, China West Normal University. She majors in teaching theory, mathematics education and in the field of statistics.

Once publicized in the core journal publishes dissertation several, and succeeds by SCI, ISTP, EI, ISR the retrieval.Once many times attended the domestic mathematics education aspect conference and related training, presently is engaged in the elementary mathematics educational work. 